\title{
OBJETIVOS DAS PRÁTICAS PEDAGÓGICAS EM EDUCAÇÃO PROFISSIONAL E TECNOLÓGICA
}

\section{OBJECTIVES OF PEDAGOGICAL PRACTICES IN PROFESSIONAL AND TECHNOLOGICAL EDUCATION}

\author{
Filipe José Cavalcanti Leite ${ }^{14}$ \\ Marcos Antônio de Oliveira ${ }^{15}$
}

Com a pretensão de apresentar e explicitar os objetivos das práticas pedagógicas em EPT e responder "quais os objetivos das práticas pedagógicas nesta modalidade de educação?", foram realizadas pesquisas bibliográficas acerca da existência de discussão sobre o tema.

A princípio, pesquisou-se através da ferramenta "Google Acadêmico". Utilizando o argumento objetivos prática pedagógica educação profissional foram obtidos 417.000 resultados. Com o lapso temporal de 10 anos (2010 - 2020) foram alcançados 24.500 resultados e a partir de 2017 (ano-referência da Lei no 13.415/2017, que estabeleceu mudanças no ensino médio) localizaram-se 15.300 resultados (acesso em: 04 fev. 2020).

Partiu-se para pesquisa em outro sítio da Internet: Revista Brasileira de Educação Profissional e Tecnológica (acesso em: 05 fev. 2020). Utilizou-se o argumento "prática pedagógica educação profissional", alcançando, entre os anos de 2017 e 2020, cinco artigos e, entre os anos de 2010 e 2020, 10 artigos.

Analisando os artigos referidos, verificou-se que não abordavam a temática pesquisada e, portanto, não havia discussões específicas referentes. Diante da ausência de textos que tratassem propriamente do tema e considerando que a caracterização dos

\footnotetext{
${ }^{14}$ Bacharel em Direito (UFPB), Especialista em Direito e Processo do Trabalho (UNIDERP) e discente do Mestrado Profissional em Educação Profissional e Tecnológica - ProfEPT/IFRN. Professor do Instituto Federal da Paraíba (IFPB) e Oficial de Justiça Avaliador Federal do TRT-7ª Região. E-mail: filipe.leite @ifpb.edu.br.

${ }^{15}$ Doutor em Recursos Naturais (UFCG), Professor do Instituto Federal do Rio Grande do Norte (IFRN), Professor do Mestrado Profissional em Educação Profissional e Tecnológica - ProfEPT (IFRN). E-mail: marcos.oliveira@ifrn.edu.br.
} 
objetivos das práticas pedagógicas facilitariam a atividade docente, percebeu-se a relevância da execução desta pesquisa para ampliação do debate acadêmico.

Uma vez que um dos pesquisadores é docente do IFPB e mestrando do Programa de Mestrado Profissional em Educação Profissional e Tecnológica (ProfEPT) no IFRN, decidiu-se pesquisar documentos normativos destas Instituições que abordassem o tema.

Localizou-se o Projeto Político Pedagógico do IFRN (volume 1 - documento base) o qual aborda, em linhas gerais, as diretrizes das práticas pedagógicas em educação. No IFPB, analisou-se o Projeto Pedagógico do Curso Técnico Integrado em Contabilidade, ofertado no Campus João Pessoa, no qual foram identificadas estratégias de ensino para EPT.

Para dar suporte teórico ao presente texto, foram utilizadas produções acadêmicas de Freire (1987), Frigotto e Araújo (2015), Moura, Lima Filho e Silva (2015), Ramos (2014), Verdum (2013), Zabala (1998), os quais discorrem sobre práticas pedagógicas, formação docente inicial e continuada, pesquisa como princípio pedagógico, trabalho como princípio educativo, interdisciplinaridade, politecnia e omnilateralidade.

Após realizar o diálogo entre o referencial teórico e as diretrizes e estratégias indicados, foi possível estabelecer os objetivos das práticas pedagógicas em EPT. Para alcançar a finalidade do artigo, abordaram-se, na primeira seção, práticas pedagógicas e seu caráter transformador. Na segunda seção, discutiu-se acerca das práticas pedagógicas em EPT e de seus princípios orientadores. Por fim, na terceira seção, tratou-se, especificamente, acerca dos objetivos das práticas pedagógicas em EPT e dos caminhos encontrados para atingi-los.

\section{PRÁTICAS PEDAGÓGICAS}

A construção do conceito de prática pedagógica se inicia a partir de "um exercício de reconstrução de nossa memória educativa" (VERDUM, 2013, p. 92). Desse modo, o professor tenta trazer, ao seu presente, fatos que o marcaram no passado, no ambiente escolar e na sua realidade, ou seja, que marcaram de certa forma sua vida e seu processo formativo.

Verdum (2013) orienta que o professor deve ser entendido como sujeito desse processo, analisando a sua trajetória pessoal e profissional as quais estabelecerão seus 
modos de atuação e suas concepções acerca do fazer pedagógico, "pois o saber profissional do professor não provém apenas da formação, da experiência, vem também da sua história de vida pessoal". Assim, as práticas pedagógicas não possuem definição própria, pois seu significado muda conforme os princípios em que estiverem baseadas.

Sob esse prisma, no exercício da docência, os autores tentam repetir experiências positivas enquanto alunos, como a realização de atividades de revisão de conteúdos na forma de jogos, vivenciadas na educação básica, e afastar as lembranças de aulas entediantes e decorativas do ensino superior.

Para Ramos (2014, p. 208), “a instauração de um processo pedagógico exige sempre que se façam as seguintes perguntas: ensinar o quê? Por quê? Como? Na verdade, o "Por quê?" antecede as demais perguntas por se referir à própria finalidade da formação".

Um dos desafios encontrados é superação do seguinte paradigma: deixar para trás a educação bancária em que as práticas pedagógicas são baseadas no professor, que se limita apenas a ser transmissor do conhecimento, e os alunos vistos como sujeitos passivos e acríticos no processo de aprendizagem apenas absorvendo o conhecimento transmitido de forma vertical, com o professor numa posição superior.

A mudança ocorreria para uma educação libertadora, mediada pela inter-relação entre professor e aluno, em que o professor é mediador do conhecimento, tentando superar uma visão da prática pedagógica como ação de transmitir conhecimento, formando alunos para que atuem criticamente na realidade em que estão inseridos, a partir de uma prática pedagógica dialógica, em que o ser humano seja visto em todas as suas dimensões (VERDUM, 2013).

Segundo Freire (1996), ensinar exige respeito aos saberes dos educandos, sugerindo discutir com os alunos a realidade em que eles vivem e relacioná-la aos conteúdos programáticos, formando cidadãos conscientes e críticos.

Dessa forma, o professor assume uma prática pedagógica revolucionária porque "ao ensinar uma disciplina, ele não está ensinando somente determinados conteúdos, mas está ensinando modos de ser e estar no mundo, atitudes em relação à realidade e convivência social" (VERDUM, 2013, p. 95). O professor que assume essa postura está preparando o aluno para o mundo do trabalho e consequentemente para buscar as mudanças e transformações sociais. 
Nessa perspectiva, entende-se que o docente deve estimular o desejo de aprender e instigar a curiosidade do discente, incentivando-o a trazer para dentro da sala de aula suas experiências pessoais relacionadas ao conteúdo programático, tornando-o agente transformador de sua realidade.

No entanto, Verdum (2013, p. 96) sinaliza que a ruptura do paradigma de práticas pedagógicas arcaicas, "baseadas na memorização, na repetição de conteúdos, na ideia de reprodução de conhecimentos" deve ser feita através da formação e capacitação de professores, a qual "tem se mostrado frágil".

Para Zabala (1995), as instituições formadoras têm insistindo em trabalhar um modelo positivista de ensino-aprendizagem, dificultando a formação de cidadãos críticos, atuantes, que ajudem na construção de uma sociedade mais justa e igualitária, contribuindo para a dicotomia teoria-prática e aumentando a fragmentação do conhecimento, constituída por disciplinas-estanques não levando em conta a realidade dos alunos. Afinal, educar quer dizer formar cidadãos e cidadãs, que não estão parcelados em compartimentos estanques, em capacidades isoladas.

Verdum (2013) expõe que a partir de uma prática reflexiva é que a ação do professor poderá assumir um caráter transformador, através de formação inicial e continuada que leve em consideração os saberes existentes nas práticas docentes.

Ainda persiste a crença de que o professor chega à escola plenamente formado, pronto para atuar em sala de aula. Exemplo disso ocorreu com um dos autores deste artigo que, ao assumir o cargo de professor, não recebeu qualquer curso de formação da Instituição e, durante o exercício do cargo, as orientações recebidas se limitam a encontros pedagógicos de um ou dois dias por semestre letivo. Como sua formação inicial em Direito não contempla disciplinas pedagógicas, precisou desenvolver, por conta própria, didáticas e metodologias de ensino para atender às necessidades dos alunos.

Zabala, (1995, p. 29) assevera que "é preciso insistir que tudo quanto fazemos em aula, por menor que seja, incide em maior ou menor grau na formação de nossos alunos". Assim, práticas integrativas orientadas possibilitam, não apenas a formação profissional, mas também a transformação social do estudante.

Após essas reflexões, analisa-se, a seguir, em que se fundamentam tais práticas quando relacionadas à EPT. 


\section{Práticas pedagógicas em educação profissional e tecnológica}

Para compreender o tema, foram identificadas práticas pedagógicas em EPT contidas no Projeto Político Pedagógico (PPP) do IFRN, as quais são orientadas por interdisciplinaridade, contextualização, flexibilidade (IFRN, 2012, p. 54), dimensões do trabalho, ciência, cultura e tecnologia (IFRN, 2012, p. 100). Os princípios orientadores destas práticas pedagógicas

[...] implicam compreender que o processo de construção/reconstrução e ampliação do conhecimento pedagógico se dá dentro e fora da sala de aula, em um movimento de encontros e desencontros; de negação, contestação e aceitação dos saberes; de possibilidades e limitações; de encantos e desencantos; de interação e mediação (IFRN, 2012, p. 60).

Nesse sentido, segundo o PPP do IFRN, essas práticas são baseadas nos conceitos "freirianos" de uma pedagogia crítica, dialógica, reflexiva e transformadora. A educação, assim, busca contribuir para um processo de formação e transformação social, objetivados também na concepção de currículo integrado.

O PPP enfoca que os processos de aprendizagem são levados em consideração para a efetivação de uma boa prática pedagógica, pois o docente deve conhecer os mecanismos de ensinar e aprender, uma vez que este processo envolve sujeitos distintos e exige metodologias e estratégias de ensino diversas. Nesse sentido, alguns pontos são "relevantes para a efetivação do processo: o que é aprender, como se aprende, quem é o sujeito da aprendizagem, o que se ensina e que metodologias de ensino podem favorecer a aprendizagem dos estudantes" (IFRN, 2012, p. 62).

O professor, antes de tudo, é um educador que não se limita a passar o conteúdo, assumindo diversas funções na sala de aula, na escola e na sociedade. Além de dominar o conhecimento, deve desenvolver outras habilidades. Assim, deve ter uma boa comunicação com alunos, pais e outros professores, escolher a melhor didática para cada assunto lecionado e estimular os discentes a refletirem, principalmente associando os aspectos estudados à realidade social. 
Dentre os princípios orientadores da prática pedagógica, abordados no PPP em questão, estão: a pesquisa como princípio pedagógico, o trabalho como princípio educativo, o respeito à diversidade e a interdisciplinaridade.

A pesquisa, como princípio pedagógico, favorece aos alunos a construção prática do conhecimento e também a transformação da realidade. Então, é de suma importância que a escola subsidie os recursos necessários para realização de pesquisa, bem como de extensão.

\begin{abstract}
É por meio da pesquisa que o professor pode desenvolver uma ação pedagógica diferenciada, aplicando o princípio da ação-reflexão-ação e relacionando a teoria e a prática de forma dialógica, contextualizada, interdisciplinar e flexível [...] Com isso, emergem os mecanismos didáticopedagógicos que visam à problematização, à busca e à construção crítica e científica do conhecimento e às interfaces do conhecimento com o cotidiano dos sujeitos, com os objetivos institucionais e com o mundo do trabalho, na perspectiva da formação integral (IFRN, 2012, p. 63).
\end{abstract}

Valer, Brognoli e Lima (2017) indicam que a pesquisa não deve ser realizada apenas no meio acadêmico, mas também na educação básica. Isso possibilitará uma qualificação da educação nacional, como defendem pensadores progressistas.

A atividade de extensão também constitui importante ferramenta para formação profissional, à medida que favorece o diálogo entre a instituição de ensino e a sociedade, trazendo o conhecimento da realidade social e devolvendo, através da prática de formação, o conhecimento para comunidade (MEDEIROS NETA, 2018).

A aplicação desse princípio se torna muito mais difícil quando os alunos são de diferentes origens, pensamentos, religiões e culturas. O professor, então, precisa adaptar a forma de ensinar ao público que vai aprender. O aluno, ao trazer sua experiência pessoal, participa do intercâmbio de realidades dentro da sala de aula, não devendo se limitar a estudar o que está sendo ensinado, mas procurar outras fontes de informações e se posicionar ativamente nesse processo.

E, para dar apoio à relação professor-aluno, a escola deve fornecer os meios necessários, propiciando um ambiente adequado de estudo, biblioteca, laboratórios, áreas livres para lazer e práticas de esportes e estimulando o contato com a comunidade que a circunda. 
O trabalho como princípio educativo, consiste na inserção do aluno no mundo do trabalho através da sua formação profissional no contexto educacional, com a integração entre ciência, cultura, tecnologia e trabalho. De acordo com o IFRN (2012, p. 64), "o entendimento do trabalho como princípio educativo orienta que os processos formativos estejam centrados na perspectiva do trabalho humano".

Nesse mesmo sentido, Ramos afirma que

o trabalho como princípio educativo está na base de uma concepção epistemológica e pedagógica que visa proporcionar aos sujeitos a compreensão do processo histórico de produção científica, tecnológica e cultural dos grupos sociais, considerada como conhecimentos desenvolvidos e apropriados socialmente para a transformação das condições naturais da vida e para a ampliação das capacidades, das potencialidades e dos sentidos humanos (RAMOS, 2014, p. 209).

Assim, o discente não se torna um mero repetidor de técnicas profissionais, que não entende cientificamente o que realiza. Ao contrário, torna-se capaz de compreender a realidade histórico-social que o circunda, de apreender novas competências relacionadas à sua área de formação e de transformar o meio social em que vive.

Outro aspecto bastante relevante adotado - nas práticas pedagógicas em EPT - é a formação humana integral e o respeito à diversidade, em que se estabelece

[...] uma relação que prima pelo respeito à pessoa humana e pela inclusão de todos; o reconhecimento da singularidade e das diferenças existentes entre as pessoas e entre os grupos; o respeito ao direito de cada indivíduo em uma sociedade democrática; a convivência com diferentes opiniões sobre a realidade e diferentes visões de mundo; o respeito aos valores e às crenças; o exercício da tolerância e da mediação dos conflitos; e o repúdio a todo tipo de discriminação (IFRN, 2012, p. 66).

A interdisciplinaridade é também um princípio norteador das práticas pedagógicas em EPT e diz respeito às interligações entre saberes de áreas distintas, pois

[...] implica uma organização curricular e didático-pedagógica pautada na integração e na contextualização de conhecimentos. [...] A interdisciplinaridade utiliza-se de estratégias de ensino e aprendizagem que possibilitam, ao mesmo tempo, um diálogo com as bases científicas, com a vida em sociedade, com a atividade produtiva e com as experiências 
subjetivas, favorecendo, aos alunos, uma formação integral (IFRN, 2012, p. 67).

Deve-se compreendê-la como “o princípio da máxima exploração das potencialidades de cada ciência, da compreensão de seus limites, mas, acima de tudo, como o princípio da diversidade e da criatividade" (ETGES apud FRIGOTTO, ARAÚJO, p. 69).

$\mathrm{Na}$ perspectiva desse princípio, o aluno se desprende de preconceitos e de posicionamentos discriminatórios, respeitando as diferenças sociais, religiosas e de gênero. O aluno ainda se torna capaz de relacionar os conteúdos das diversas disciplinas estudadas, à sua formação profissional, às suas experiências pessoais e ao contexto social em que vive.

Nessa seara, subsidiado pelos princípios destacados, apresentam-se em seguida os objetivos das práticas pedagógicas, objeto da presente pesquisa.

\section{OBJETIVOS DAS PRÁTICAS PEDAGÓGICAS EM EDUCAÇÃO PROFISSIONAL E TECNOLÓGICA}

Após a abordagem de conceitos importantes acerca de práticas pedagógicas em geral e, especialmente, das práticas em EPT, apresentam-se alguns objetivos relacionados a essas práticas. Segundo Freire,

Toda prática educativa demanda a existência de sujeitos, um, que ensinando, aprende, outro, que aprendendo, ensina [...]; a existência de objetos, conteúdos a serem ensinados e aprendidos envolve o uso de métodos, de técnicas, de materiais, implica, em função de seu caráter diretivo/objetivo, sonhos, utopia, ideais [...] (FREIRE,1998, p. 77).

A prática educativa também deve ser entendida como um exercício constante em favor da produção e do desenvolvimento da autonomia de educadores e educandos, contribuindo para que o aluno seja o artífice de sua formação com a ajuda necessária do professor (IFPB, 2011). 
Neste estudo, os objetivos das práticas pedagógicas em EPT baseiam-se no PPP do IFRN e no PPC do Curso Técnico Integrado em Contabilidade do IFPB, como anteriormente explicitado.

De acordo com o PPP do IFRN (2012, p. 70) "no que concerne à educação, uma diretriz pedagógica diz respeito à organização e à gestão do fazer pedagógico. Nesse norte, contemplam-se ações, conteúdos e metodologias de ensino e aprendizagem".

No que se refere à EPT, deve-se mediar a aquisição de conhecimento e a aplicação destes em casos concretos e na resolução de conflitos. Para isso, podem ser utilizadas algumas estratégias de ensino com diversidade de ações:

[...] utilização de aulas práticas, na qual os alunos poderão estabelecer relações entre os conhecimentos adquiridos e as aulas práticas; através de aulas expositivas, dialogadas para a construção do conhecimento nas disciplinas; pesquisas sobre os aspectos teóricos e práticos no futuro campo de atuação; discussão de temas partindo-se de leituras orientadas (individuais e em grupos), de vídeos, pesquisas e aulas expositivas; estudos de caso, através de simulações de casos reais nos espaços de futura atuação do técnico; debates provenientes de pesquisa prévia, de temas propostos para a realização de trabalhos individuais e/ou em grupos; seminários apresentados pelos alunos, professores e também por profissionais de diversas áreas de atuação; abordagem de assuntos relativos às novas tecnologias da informação e da comunicação; dinâmicas de grupo; palestras com profissionais da área, tanto na instituição de ensino como também nos espaços de futura atuação do discente; visitas técnicas (IFPB, 2011, p. 25).

Percebe-se que essas estratégias, quando aplicadas em conjunto, destacam-se em busca da politecnia, da multiplicidade de técnicas e conhecimentos, das mais diversas formas de ensino-aprendizagem e da articulação entre cultura, conhecimento, tecnologia e trabalho. Esse prévio contato, através do encontro com o campo epistêmico do conhecimento, permite pensar na educação numa perspectiva de formação para o trabalho.

A politecnia, por sua vez, é materializada a partir do momento em que proporciona aos educandos 0 acesso a fundamentos científicotecnológicos, sócio-históricos e culturais da produção moderna, o que permite a realização, de forma mais consciente e autônoma, de suas escolhas profissionais (RAMOS, 2014, p. 209). 
Ademais, possibilita a formação do sujeito omnilateral, isto é capaz de pensar na perspectiva de múltiplas direções, utilizando a práxis integradora, qual seja o conjunto de teoria, prática e transformação de forma integrada.

Para Ramos (2014, p.209), “a omnilateralidade da formação implica a apreensão do mundo pelos homens por meio dos conhecimentos das propriedades do mundo real (ciência), de valorização (ética) e de simbolização (arte), o que tem sido reconhecido como conhecimentos da formação geral".

Nessa mesma direção aponta o PPP do IFRN (2012, p. 70), ao destacar que "as diretrizes pedagógicas orientam as ações que constituem os processos educacionais, articulando ensino, pesquisa e extensão". Assim, garantem-se aos estudantes a aquisição dos mais diversos conhecimentos e habilidades em busca da formação humana integral.

Destacam-se entre as principais diretrizes da prática pedagógica em EPT são “o planejamento pedagógico, a avaliação da aprendizagem, os projetos integradores, a prática profissional, o trabalho de conclusão de curso, os seminários curriculares e os perfis esperados do professor e do aluno" (IFRN, 2012, p. 70).

A partir dessa reflexão, podem ser construídos os objetivos das práticas pedagógicas em EPT.

\section{Utilização conjunta de estratégias de ensino em busca da afirmação da politecnia}

Pretende-se que sejam utilizadas aulas práticas, pesquisas sobre os aspectos teóricos e práticos no futuro campo de atuação, discussão de temas partindo-se de leituras orientadas, estudos de caso, dinâmicas de grupo, abordagem de assuntos relativos às novas tecnologias da informação e da comunicação, de acordo com o planejamento pedagógico das diversas disciplinas, em busca de uma da multiplicidade de técnicas e conhecimentos, de metodologias educativas, e das mais diversas formas de ensino-aprendizagem que conjuguem cultura, conhecimento, tecnologia e trabalho.

Conforme apontam Moura, Lima Filho, Silva (2015, p. 1061), "é pela formação politécnica que se daria a formação intelectual, física e tecnológica, o que sugere que o conceito de politecnia pode abarcar a ideia de formação humana integral”. 
Para ilustrar, cita-se a experiência vivenciada na disciplina Noções de Direito Público e Privado (NDPP) lecionada por um dos autores desse trabalho em turmas da primeira série do Curso Técnico Integrado Em Contabilidade no IFPB - Campus João Pessoa.

O conteúdo programático da disciplina NDPP compreende os diversos tipos de normas, a organização político-administrativa do Estado, o sistema de escolha de seus representantes e o processo de elaboração das leis.

Os alunos são estimulados a ler o Regulamento do Ensino Técnico do IFPB e partes da Constituição Federal (1988) e da Lei de Diretrizes e Bases da Educação Brasileira (Lei no 9.394, de 20 de dezembro de 1996) que abordam essa modalidade de educação. Problematiza-se sobre quem criou essas normas, as motivações e o contexto histórico daquele momento, os tipos de normas existentes no Direito brasileiro, o quórum mínimo necessário para aprovação e modificação das normas, a hierarquia das normas e a eficácia de cada uma. Ao final, os alunos são orientados pelo professor a criarem uma norma para regulamentação da dinâmica existente na sala de aula, que contemple critérios de pontuação pela participação nas atividades e a correção dos textos elaborados.

Desse modo, os discentes se tornam capazes de associar os conteúdos teóricos da disciplina NDPP a outros conhecimentos científico-tecnológicos, à realidade social que os cerca e aos aspectos históricos que os fundamentam. Desde o início do curso, os estudantes aprendem e praticam um procedimento que constantemente será exigido dos futuros técnicos em Contabilidade que precisarão ler e aplicar normas tributárias e regulamentos contábeis.

\section{Contato prévio com o mundo do trabalho, permitindo o encontro com o campo epistêmico do conhecimento}

Através da prática profissional, da elaboração do trabalho de conclusão de curso, deve-se promover o pensamento da educação a partir desta para o trabalho.

Conforme explica Araújo,

O conteúdo político contrahegemônico, uma epistemologia fundada na ideia de práxis e a possibilidade de interação pedagógica entre trabalho e educação na perspectiva da revolução social são os elementos que podem 
conduzir à formulação de objetivos educacionais integradores (ARAÚJO, 2014, p. 46).

Guiados por esse objetivo e utilizando como referência as práticas pedagógicas utilizadas no curso técnico mencionado, os alunos devem realizar estágio curricular, nos termos do Projeto Pedagógico do Curso (PPC) e da Lei de estágio de estudantes (Lei no 11.788, de 25 de setembro de 2008), para aplicar os conteúdos teóricos estudados à prática profissional. A fim de disponibilizar essas vagas de estágios, a Coordenação do Curso de Contabilidade realiza a interveniência com escritórios de contabilidade e instituições públicas.

Nessa relação tripartite (Instituição de Ensino, Organização concedente e estudante), o supervisor de estágio da parte concedente avalia o estagiário quanto às atividades desempenhadas e dialoga com o professor-orientador da Instituição de Ensino, o qual analisa a adequação daquelas atividades ministrado ao currículo do curso e ao perfil profissional de formação. No final do estágio, o estudante prepara relatório no qual descreve sobre sua aprendizagens e conhecimentos construídos no ambiente organizacional com a tutoria do supervisor de estágio e do professor-orientador.

Os estudantes elaboram um Trabalho de Conclusão de Curso (TCC), que pode ser relacionado ao estágio ou não, sob orientação de um professor da Instituição e avaliado por uma banca formada pelo orientador e outros dois professores, após exposição oral.

Mediante tais práticas, torna-se possível o prévio e efetivo contato do discente com o mundo do trabalho, o que lhe permitirá a mobilização dos conhecimentos obtidos no curso para resolver problemas práticos de sua área de formação.

\section{Orientação do discente por meio da práxis integradora, permitindo a formação do sujeito omnilateral}

Por meio da execução de projetos integradores, de visitas técnicas e de seminários curriculares apresentados pelos alunos, professores e também por profissionais de diversas áreas de atuação, o discente será capaz de pensar na perspectiva de múltiplas direções.

Corroborando com esse objetivo, Frigotto e Araújo orientam que 
Aulas expositivas, estudo do meio, jogos didáticos, visitas técnicas Integradas, seminários, estudo dirigido, oficinas e várias outras estratégias de ensino e aprendizado podem servir tanto para projetos conservadores, tradicionais, conformadores das capacidades humanas, quanto para projetos libertários, comprometidos com a ampliação das capacidades humanas (FRIGOTTO, ARAÚJO, p. 76).

Nessa perspectiva, usando como parâmetro o já citado Curso de Contabilidade, os estudantes são estimulados a participarem de projetos de extensão com os professores da Unidade Acadêmica de Gestão e Negócios (UAG), a apresentarem trabalhos e a participarem das oficinas e minicursos no Seminário de Inovação Tecnológica (SINTIF), a conhecerem a realidade de pequenas, média e grandes empresas da região, através de visitas técnicas a comércio e à feira do bairro onde se localiza o Campus João Pessoa do IFPB, bem como à montadora de automóveis e a restaurante de rede de fastfoods.

Os egressos, aptos a trabalharem na área de formação, podem continuar seus estudos na mesma área, optando por cursar o bacharelado em Ciências Contábeis, ou em áreas correlatas, ao optarem por curso superior em Administração de Empresas, Economia ou Direito. Destaca-se que o IFPB oferta apenas o bacharelado em Administração de Empresas dentre as opções indicadas.

No entanto, como os discentes desenvolveram diversas outras habilidades e vivenciaram múltiplas experiências no ensino médio integrado, estão preparados para outros desafios em novas áreas do conhecimento, graças às perspectivas diferenciadas do sujeito omnilateral.

\section{CONSIDERAÇÕES FINAIS}

Verifica-se que o campo de produção e discussão acadêmica acerca de práticas educativas mostra-se bastante profícuo. Apresentam-se estratégias de aprendizagem, metodologias de ensino e diretrizes pedagógicas em busca de práticas docentes mais efetivas. 
A educação bancária, a abordagem tradicional de ensino baseada em métodos unicamente conteudistas, que não se preocupam com a formação humana integral, tem sido cada vez mais questionada pelos educadores.

No que concerne à EPT, as práticas pedagógicas têm sido orientadas para uma educação integral, politécnica, preocupada com a formação do sujeito omnilateral, que propicie o trabalho enquanto princípio educativo.

Assim como em todas as demais ciências humanas, na educação não há fórmulas prédeterminadas para o êxito dessas pretensões. Nesse contexto, identificam-se muitas variáveis, tais como condições das escolas, formação dos docentes e realidade social dos alunos.

No entanto, constatam-se diversas experiências exitosas como as do IFRN e do IFPB apresentadas neste trabalho, as quais apontam caminhos viáveis que podem ser trilhados para busca de uma EPT promotora do desenvolvimento omnilateral dos sujeitos.

Após as reflexões apresentadas e a experiência professoral vivenciada por um dos autores da pesquisa, constata-se que a utilização de estratégias adequadas de ensino tais como descritas neste trabalho, em consonância com as diretrizes pedagógicas respectivas, podem favorecer ao docente o alcance dos objetivos das práticas pedagógicas em EPT.

Por fim, diante da ausência de outras pesquisas específicas e da importância do tema para formação profissional e tecnológica, exsurge a possibilidade de ampliação do debate por meio do compartilhamento de experiências docentes e da realização de novas pesquisas referentes ao tema.

\section{REFERÊNCIAS}

ARAÚJO, R. M. de L. Práticas Pedagógicas e Ensino Integrado. Curitiba: Instituto Federal do Paraná, 2014. - (Coleção Formação Pedagógica; v. 7). Disponível em: https://curitiba.ifpr.edu.br/wp-content/uploads/2016/05/Pr\%C3\%A1ticaspedag\%C3\%B3gicas-e-ensino-integrado.pdf. Acesso em: 4 maio 2020.

FREIRE, J. B. Pedagogia do Futebol. Rio de Janeiro: Ney Pereira Editora Ltda, 1998.

FREIRE, P. Pedagogia do Oprimido. 17 ed. Rio de Janeiro: Paz e Terra, 1987. 
. Pedagogia da Autonomia: saberes necessários à prática educativa. 25 ed. São Paulo: Paz e Terra, 1996.

FRIGOTTO, G.; ARAÚJO, R. M. de L. Práticas Pedagógicas e ensino integrado. Revista Educação em Questão, v. 52, p. 61-80, 2015. Disponível em: https://doi.org/10.21680/19811802.2015v52n38ID7956. Acesso em: 4 maio 2020.

IFPB - Instituto Federal de Educação, Ciência e Tecnologia da Paraíba. Projeto Pedagógico do Técnico em Contabilidade Integrado ao Ensino Médio. João Pessoa-PB, 2011. Disponível em: https://drive.google.com/file/d/OB2dLTFTdVbI1NnE3akVFVWhZRWc/view. Acesso em: 5 fev. 2020.

IFRN - Instituto Federal de Educação, Ciência e Tecnologia do Rio Grande do Norte. Projeto Político Pedagógico do IFRN: uma Construção Coletiva. Documento-base. Volume 1. Aprovado pela Resolução 38/2012 - CONSUP/IFRN, de 26/03/2012. Natal-RN, 2012. Disponível em: https://portal.ifrn.edu.br/ifrn/institucional/projeto-politico-pedagogico1/lateral/menu-1/volume-1-documento-base. Acesso em: 5 fev. 2020.

MEDEIROS NETA, O. M. et al. Extensão e Formação na Educação Profissional. Revista Brasileira da Educação Profissional e Tecnológica, [S.I.], v. 1, n. 14, p. e7101, jun. 2018. ISSN 2447-1801. Disponível em:

http://www2.ifrn.edu.br/ojs/index.php/RBEPT/article/view/7101. Acesso em: 5 maio 2020.

MOURA, D. H.; LIMA FILHO, D. L.; SILVA, M. R. Politecnia e formação integrada: confrontos conceituais, projetos políticos e contradições históricas da educação brasileira. Revista Brasileira de Educação, v. 20, p. 1057-1080, 2015. Disponível em: http://www.scielo.br/scielo.php?script=sci_arttext\&pid=S141324782015000401057\&lng=en\&nrm=iso. Acesso em: 4 maio 2020.

RAMOS, M. Filosofia da Práxis e Práticas Pedagógicas de Formação de Trabalhadores. Trabalho \& Educação, v. 23, n. 1, p. 207-218, 19 abr. 2014. Disponível em: https://periodicos.ufmg.br/index.php/trabedu/article/view/9306. Acesso em: 4 maio 2020.

VALER, S.; BROGNOLI, Â.; LIMA, L. A pesquisa como princípio pedagógico na educação profissional técnica de nível médio para a constituição do ser social e profissional. Fórum Linguístico, Florianópolis, v. 14, n. 4, p. 2785-2803, dez. 2017. ISSN 1984-8412. Disponível em: https://periodicos.ufsc.br/index.php/forum/article/view/1984-8412.2017v14n4p2785. Acesso em: 5 maio 2020.

VERDUM, P. Prática Pedagógica: o que é? O que envolve? Revista Educação por Escrito PUCRS, v.4, n.1, jul.2013. Disponível em: http://revistaseletronicas.pucrs.br/ojs/ index.php/porescrito/article/view/14376. Acesso em: 29 fev. 2020.

ZABALA, A. A prática educativa: como ensinar. Porto Alegre: Artmed Editora, 1998. 